\title{
KONSELING GIZI DAN PERUBAHAN PERILAKU PASIEN DISLIPIDEMIA YANG MENDAPAT BOOKLET DAN LEAFLET DI RSI SITI KHADIJAH PALEMBANG
}

\author{
Nisrina Luthfiyah, Susyani, Imelda Telisa \\ Politeknik Kementrian Kesehatan Palembang, Prodi D-IV Gizi \\ susyani@poltekkespalembang.ac.id
}

\begin{abstract}
Dyslipidemia is a disorder of lipid metabolism that characterized by the increasing or decreasing lipid fraction plasma. A dyslipidemia may be caused by genetic, age, gender, nutritional intake and smoking habit. Lipid level abnormality is one of the risk factors for cardiovascular and metabolic disease. Management of dyslipidemia includes pharmacological and non-pharmacological therapy that can be supported through nutritional counselling. The study is to know the effect of nutritional counseling on the behavior of dyslipidemia patients who received booklet and leaflet at Siti Khadijah Islamic Hospital in Palembang. The research design is a quasi-experiment with a pretest and posttest. The research was conducted on January until March 2019. The data analysis uses the Wilcoxon and Mann Whitney tests. Wilcoxon test result shows that nutritional counseling in both groups equally gave effect to knowledge, attitudes and actions. Mann Whitney Test conducted on both groups of knowledge obtained $p$ value of 0.274 , the attitude obtained $p$ value of 0.010 and the action obtained $p$ value of 0.065 . There was no difference between booklet and leaflet groups, to increase their knowledge and action, however there is a difference between booklet and leaflet groups to attitude improvement of booklet and leaflet groups, where leaflets influence more in increasing a better respondent attitudes to implement dyslipidemia diet.
\end{abstract}

Key Words : Nutrition Behavior, Dyslipidemia, Nutrition Counseling, Booklet, Leaflets.

\begin{abstract}
Abstrak: Dislipidemia adalah kelainan metabolisme lipid yang ditandai dengan peningkatan maupun penurunan fraksi lipid dalam plasma. Dislipidemia dapat disebabkan karena faktor genetik, usia, jenis kelamin, asupan zat gizi dan merokok. Abnormalitas kadar lipid dalam darah merupakan salah satu faktor risiko timbulnya penyakit kardiovaskular dan metabolik. Asupan zat gizi yang lebih dari standar kebutuhan akan menyebabkan rerata rasio kadar kolesterol total/HDL diatas normal. Penatalaksanaan dislipidemia mencakup terapi farmakologis dan non farmakologis yang dapat didukung melalui pemberian konseling gizi. Tujuan penelitian ini untuk mengetahui adanya pengaruh pemberian konseling gizi terhadap perilaku pasien dislipidemia yang mendapat booklet dan leaflet di RSI Siti Khadijah Kota Palembang. Desain penelitian adalah quasi experiment dengan rancangan penelitian pretest dan posttest. Penelitian dilakukan pada bulan Januari-Maret 2019. Analisis data menggunakan uji Wilcoxon dan Mann Whitney. Pada uji Wilcoxon didapatkan hasil jika konseling gizi pada kedua kelompok sama-sama memberikan pengaruh terhadap pengetahuan, sikap dan tindakan. Berdasarkan Uji Mann Whitney yang dilakukan pada kedua kelompok terhadap pengetahuan didapatkan nilai $\mathrm{p}$ sebesar 0,274, terhadap sikap didapatkan nilai $\mathrm{p}$ sebesar 0,010 dan terhadap tindakan didapatkan nilai $\mathrm{p}$ sebesar 0,065 . Tidak ada perbedaan peningkatan pengetahuan dan tindakan antara kelompok booklet dan leaflet namun ada perbedaan peningkatan sikap antara kelompok booklet dan leaflet dimana leaflet lebih berpengaruh dalam meningkatkan sikap responden menjadi lebih baik dalam menjalankan diet dislipidemia.
\end{abstract}

Kata Kunci : Booklet, Dislipidemia, Konseling Gizi, Leaflet,Perilaku Gizi 
Dislipidemia merupakan kelainan sebanyak 8602 pasien. Terdapat pasien metabolisme lipid yang ditandai dengan Hipertensi pada tahun 2015 sebanyak 8612 ketidaknormalan kadar lipid dalam plasma. pasien, pada tahun 2016 sebanyak 3292 Kelainan lipid yang terjadi antara lain pasien dan pada tahun 2017 sebanyak 1521 kenaikan kolesterol total, LDL, trigliserida pasien. Terdapat juga pasien Stroke pada dan penurunan kadar HDL (Anwar,Tanvir., 2004). Kadar lipid dalam darah yang tidak normal merupakan faktor risiko terjadinya penyakit kardiovaskular dan metabolik, seperti aterosklerosis, penyakit jantung koroner, stroke, sindrom metabolik dan sebagainya (Riset Kesehatan Dasar, 2013.).

Proporsi penduduk Indonesia dengan usia >15 tahun, merujuk nilai yang ditentukan pada NCEP-ATP III dengan kadar kolesterol total di atas nilai normal adalah sebesar $35.9 \%$, kadar LDL diatas nilai normal dengan kategori near optimal dan borderline adalah sebesar $60.3 \%$, dan kategori kadar LDL tinggi dan sangat tinggi adalah sebesar $15.9 \%$, kadar trigliserida di atas nilai normal dengan kategori borderline adalah sebesar $13.0 \%$ dan kategori gabungan tinggi-sangat tinggi adalah sebesar $11.9 \%$, kadar HDL dengan kategori di bawah nilai normal adalah sebesar $22.9 \%$ (Riset Kesehatan Dasar, 2013)

Berdasarkan data rekam medik RSI Siti Khadijah Kota Palembang bagian rawat jalan, pada tahun 2015 terdapat pasien Hypertensive Heart Desease (HHD) sebanyak 8077 pasien, pada tahun 2016 sebanyak 5304 pasien dan pada tahun 2017 mengalami peningkatan dengan pasien tahun 2015 sebanyak 1437 pasien, pada tahun 2016 sebanyak 1272 pasien dan pada tahun 2017 mengalami peningkatan dengan pasien sebanyak 1941 pasien (Rekam Medik RSI Khadijah. 2018). Ketiga penyakit tersebut dapat disebabkan karena terjadinya abnormalitas lipid dalam darah (dislipidemia).

Asupan zat gizi yang lebih dari standar kebutuhan akan menyebabkan rerata rasio kadar kolesterol total/HDL diatas normal ( Emy, 2015). Selain diet DASH, di Indonesia sendiri menurut Perhimpunan Dokter Spesialis Karidovaskular Indonesia (PERKI) penatalaksanaan dislipidemia mencakup 2 terapi yaitu farmakologis dengan penggunaan obat-obat penurun kolesterol dan nonfarmakologis dengan Therapeutic Lifestyle Changes (TLC) (PERKI, 2013). Dalam penelitian Aurora Ruth dkk (2012) konseling merupakan salah satu faktor yang dapat mendukung TLC (Aurora, Ruth.,dkk, 2012)

Tindakan konseling dapat merubah perilaku kesehatan seseorang yaitu dengan melalui pendidikan kesehatan yang dimana hal tersebut dapat mempengaruhi perilaku (pengetahuan, sikap dan tindakan) pasien. 
Seorang konselor membutuhkan perantara berupa media saat melakukan konseling diantaranya dapat menggunakan media booklet dan leaflet (Refdi, Fhani, tahun 2013.).

Masih tingginya angka kejadian penyakit kardiovaskular yang disebabkan oleh dislipidemia maka peneliti tertarik untuk melakukan penelitian mengenai pengaruh dari pemberian konseling gizi terhadap perilaku (pengetahuan, sikap dan tindakan) pasien dislipidemia rawat jalan yang diberikan media booklet atau leaflet $\mathrm{Di}$ RSI Siti Khadijah Kota Palembang.

\section{BAHAN DAN CARA KERJA}

Penelitian ini bersifat quasi eksperiment dengan rancangan pretest and posttest. Variabel dependen dalam penelitian ini adalah perilaku (pengetahuan, sikap dan tindakan) dan variabel independen dalam penelitian ini adalah pemberian konseling gizi. Subjek penelitian ini adalah penderita penyakit dislipidemia rawat jalan Di RSI Siti Khadijah Palembang. Penelitian dilakukan pada bulan Januari - Maret 2019. Kriteria inklusi penelitian ini adalah berusia $>18$ tahun, berdomisili di Kota Palembang, pasien dislipidemia yang belum pernah mendapatkan konseling, pasien rawat jalan, dapat berkomunikasi dengan baik dan dapat membaca dan menulis.

Penentuan responden dilakukan dengan metode purposive sampling. Jumlah responden masing - masing 30 untuk tiap kelompok. Kelompok booklet mendapatkan konseling gizi yang menggunakan media booklet yang diberikan selama 3 kali setiap 1 kali sekali dalam 3 hari, sedangakan kelompok leaflet mendapatkan konseling gizi yang menggunakan media leaflett yang diberikan selama 3 kali setiap 1 kali sekali dalam 3 hari.

Pengetahuan, sikap dan tindakan sebelum perlakuan diiukur menggunakan kuisioner kemudian diukur kembali setelah diberikan perlakuan selama 3 kali pertemuan dengan menggunakan kuisioner kembali. Data status gizi didapatkan menggunakan pengukuran antropometri, sedangkan data karakteristik responden didapatkan menggunakan formulir identitas responden dengan wawancara langsung.

Uji statistik menggunakan program SPSS. Uji normalitas menggunakan uji Kolmogorov-Smirnov. Karakteristik responden dianalisis menggunakan analisis deskriptif. Perbedaan variabel (pengetahuan, sikap dan tindakan) sebelum dan sesudah perlakuan pada kedua kelompok diuji dengan Wilcoxon-test. Perbedaan pengaruh perlakuan kedua kelompok terhadap perilaku dianalisis menggunakan uji mann-whitney.

\section{HASIL}

\section{Karakteristik Responden}


Karakteristik responden terdiri dari usia, jenis kelamin, pendidikan dan pekerjaan disajikan dalam tabel 1.

Tabel 1. Karakteristik Responden

\begin{tabular}{lcccc}
\hline Karakteristik & \multicolumn{3}{c}{ Booklet } & Leaflet \\
\cline { 3 - 5 } Responden & $\mathrm{n}$ & $\%$ & $\mathrm{n}$ & $\%$ \\
\hline Usia & & & & \\
$\quad<59$ tahun & 4 & 13.3 & 3 & 10 \\
60-69 tahun & 19 & 63.3 & 17 & 56.7 \\
70-79 tahun & 6 & 20 & 10 & 33.3 \\
$\quad>80$ tahun & 1 & 3.3 & 0 & 0 \\
Jenis Kelamin & & & & \\
Laki-laki & 10 & 33.3 & 11 & 36.7 \\
Perempuan & 20 & 66.7 & 19 & 63.3 \\
Pendidikan & & & & \\
SD & 1 & 3.3 & 0 & 0 \\
SMP & 1 & 3.3 & 0 & 0 \\
SMA & 14 & 46.7 & 24 & 80 \\
Akademi/PT & 14 & 46.7 & 6 & 20 \\
Pekerjaan & & & & \\
IRT & 10 & 33.3 & 11 & 36.7 \\
PNS & 2 & 6.7 & 2 & 6.7 \\
Pensiunan & 18 & 60.0 & 17 & 56.7 \\
\hline
\end{tabular}

Perbedaan skor perilaku (pengetahuan, sikap dan tindakan ) sebelum dan sesudah

Rata - rata skor perilaku (pengetahuan, sikap dan tindakan) sebelum dan sesudah perlakuan disajikan dalam tabel 2 .

Tabel 2. Perbedaan rerata Skor Perilaku

\begin{tabular}{|c|c|c|c|c|}
\hline Variabel & $\begin{array}{l}\text { Kelompo } \\
\mathrm{k}\end{array}$ & $\begin{array}{l}\text { Mean } \\
\text { awal } \pm \\
\text { SD }\end{array}$ & $\begin{array}{l}\text { Mean } \\
\text { akhir } \pm \\
\text { SD }\end{array}$ & $\mathrm{P}$ \\
\hline \multirow{3}{*}{$\begin{array}{l}\text { Pengetahu } \\
\text { an }\end{array}$} & Bookle & $0.60 \pm 0$ & $4.40 \pm 0.8$ & 0.0 \\
\hline & $t$ & 968 & 14 & 00 \\
\hline & Leaflet & $\begin{array}{l}0.23 \pm 0 . \\
504\end{array}$ & $\begin{array}{l}3.83 \pm 0.7 \\
91\end{array}$ & $\begin{array}{l}0.0 \\
00\end{array}$ \\
\hline \multirow{3}{*}{ Sikap } & Bookle & $2.03 \pm 1$. & $4.93 \pm 0.3$ & 0.0 \\
\hline & $t$ & 671 & 65 & 00 \\
\hline & Leaflet & $\begin{array}{l}0.80 \pm 1 \\
562\end{array}$ & $\begin{array}{l}4.83 \pm 0.3 \\
79\end{array}$ & $\begin{array}{l}0.0 \\
00\end{array}$ \\
\hline \multirow{3}{*}{ Tindakan } & Bookle & $0.97 \pm 1$ & $2.97 \pm 0.9$ & 0.0 \\
\hline & $t$ & 033 & 28 & 00 \\
\hline & Leaflet & $\begin{array}{l}1.40 \pm 1 . \\
163\end{array}$ & $\begin{array}{l}2.90 \pm 0.8 \\
45\end{array}$ & $\begin{array}{l}0.0 \\
00\end{array}$ \\
\hline
\end{tabular}

Penelitian ini didapatkan hasil bahwa pemberian konseling gizi dapat meningkatkan perilaku responden. Hasil uji statistik (Uji Wilcoxon) pada kelompok booklet dan leaflet sama-sama mendapatkan nilai $\mathrm{p}=0.000$ berarti alpha $5 \%$ terlihat ada pengaruh yang signifikan terhadap peningkatan pengetahuan, sikap dan tindakan pada kelompok booklet maupun kelompok leaflet

\section{Pengaruh Pemberian Konseling Gizi Terhadap Perilaku}

Pengaruh pemberian konseling gizi terhadap perilaku (pengetahuan, sikap dan tindakan) disajikan dalam tabel 3.

Tabel 3. Pengaruh Pemberian Konseling Gizi

\begin{tabular}{lccc}
\hline Variabel & $\begin{array}{c}\text { Kelompo } \\
\mathrm{k}\end{array}$ & $\begin{array}{c}\text { Perbedaa } \\
\mathrm{n} \text { Mean }\end{array}$ & $\mathrm{P}$ \\
\hline Pengetahuan & Booklet & 3.80 & 0.274 \\
& Leaflet & 3.60 & \\
Sikap & Booklet & 2.90 & 0.010 \\
& Leaflet & 4.03 & \\
Tindakan & Booklet & 2.00 & 0.065 \\
& Leaflet & &
\end{tabular}

Hasil uji statistic dari pengaruh pemberian konseling gizi terhadap peningkatan sikap dengan menggunakan media booklet dan leaflet melalui Uji MannWhitney didapatkan nilai $\mathrm{p}=0.010(\mathrm{p}<0.05)$ sehingga dapat disimpulkan bahwa ada perbedaan peningkatan sikap antara kelompok booklet dan leaflet.

PEMBAHASAN 
Karakteristik responden dalam lebih tahan lama. Booklet biasanya penelitian ini sebagian besar berusia 60-69 digunakan untuk tujuan peningkatan tahun, berjenis kelamin perempuan, pengetahuan, karena booklet memberikan berpendidikan SMA dan memiliki pekerjaan informasi yang lebih spesifik. Keterbatasan sebagai pensiunan.

Usia sesorang dapat berpengaruh pada kadar kolesterol total. Seiring bertambahnya usia maka kadar kolesterol totalnya relatif lebih tinggi pada usia muda, hal ini dikarenakan semakin berkurangnya aktifitas reseptor LDL. Sel reseptor ini berfungsi sebagai hemostasis pengatur peredaran kolesterol dalam darah dan banyak terdapat dalam hati, kelenjar gonad dan kelenjar adrenal. Adanya gangguan pada sel reseptor akan meningkatkan kadar kolesterol dalam darah (Listiana, L dan Purbosari,T., 2006).

Hasil penelitian perempuan lebih banyak yang menderita penyakit dislipidemia dibandingkan dengan laki laki. Beberapa penelitian membuktilan Perempuan yang telah menopose cenderung memiliki kadar kolesterol yang lebih tinggi dibandingkan laki-laki dewasa dikarenakan berkurangnya aktifitas hormone estrogen. Hormone esterogen berperan penting dalam mengendalikan kadar kolesterol, dan juga berfungsi sebagai antioksidan. Hormon estrogen dapat mencegah terjadinya oksidasi kolesterol LDL sehingga dapat mengurangi plak pada pembuluh darah (Ujiani, Sri., 2014).

Sebagai media cetak, booklet memiliki kelebihan dapat dibuat dengan mudah dan booklet sebagaimedia cetak perlu waktu yang lama untuk mencetak tergantung dari dari pesan dan alat, dapat mengurangi minat pembaca jika terlalu banyak dan panjang dan perlunya perawatan yang intensif (Gustaning, Guni., 2014)

Media leaflet juga memiliki kelebihan dimana leaflet dipilih karena dianggap memiliki nilai praktis. Informasi yang disampaikan hanya secara garis besar saja sehingga membuat pembaca secara langsung memahami poin-poin pesan yang ingin dispaikan dalam media leaflet tersebut. Namun media leaflet juga memiliki kekurangan dimana terkadang media leaflet menggunakan huruf yang terlalu kecil dan materi yang disampaikan tidak bisa terlalu banyak (Fitriani, Arifah., 2013).

Peningkatan skor pengetahuan setelah diberikan konsultasi sejalan dengan hasil penelitian yang dilakukan Azzahra dan Muniroh (2015) mengenai hubungan konseling terhadap pengetahuan dan sikap didapatkan hasil bahwa konseling sangat berpengaruh terhadap peningkatan pengetahuan $(\mathrm{p}=0.005)$. Penelitian Afriska dkk (2018) menunjukkan bahwa ada pengaruh perubahan pengetahuan gizi yang bermakna sebelum dan sesudah intervensi pendidikan gizi selama 2 kali dalam 
seminggu (10-15 menit) selama 3 minggu. Penelitian Meli $\operatorname{dkk}(2019)$ Hasil penelitian menunjukkan ada pengaruh signifikan antara konseling gizi dengan pengetahuan ( $p$ $=0,000)$

Peningkatan skor sikap setelah diberikan konsultasi sejalan dengan hasil penelitian yang dilakukan Azzahra dan Muniroh (2015) mengenai hubungan konseling terhadap pengetahuan dan sikap didapatkan hasil bahwa konseling sangat berpengaruh terhadap peningkatan sikap $(\mathrm{p}=0.014)(11)$. Peningkatan tindakan sejalan dengan penelitian Rahmawati dkk (2017) menunjukkan bahwa selain dapat merubah pengetahuan dan sikap seseorang, konseling juga mampu merubah tindakan (kepatuhan) seseorang menjadi lebih baik (Rahmawati.,dkk, 2017)

Kelompok leaflet memiliki rata-rata mean sikap yang lebih tinggi dibandingkan kelompok booklet sehingga dapat disimpulkan media leaflet lebih berpengaruh

\section{DAFTAR RUJUKAN}

Afriska L, Anang W, Emy Y.2018.Konseling Gizi pada Remaja Obesitas. Jurnal Media Kesehata, Vol.11 No.1 Juni 2018. hal 071-101

Anwar, Tanvir. 2004. Dislipidemia Sebagai Faktor Risiko PJK. Available from: URL: https://www.researchgate.net/publication/423214 31_Dislipidemia_Sebagai_Faktor_Resiko_Penya kit_Jantung_Koroner

Aurora, Ruth., Sinambela, Urika., Noviyanti, Carolina. 2012. Peran Konseling Berkelanjutan Pada Penanganan Pasien Dislipidemia.

Azzahra, Margareta., Muniroh, Lailatul. 2015. Pengaruh Konseling Terhadap Penegtahuan terhadap peningkatan sikap responden. Hal tersebut bisa disebabkan karena salah satu keunggulannya dimana media leaflet menyampaikan informasi secara singkat sehingga membuat responden langsung memahami kalimat tersebut dibandingkan dengan booklet yang dapat mengurangi minat pembaca jika terlalu banyak dan panjang

\section{KESIMPULAN}

Konseling dengan menggunakan leaflet terbukti lebih berpengaruh dalam meningkatkan perubahan sikap penderita dyslipidemia dalam menyikapi tatalaksana diet dyslipidemia. Hal tersebut dapat dikarenakan informasi dari media leaflet lebih singkat dan mudah dimengerti. Konseling dengan menggunakan media booklet dan leaflet dapat meningkatkan pengetahuan dan sikap namun tidak bisa menjamin untuk merubah tindakan responden menjadi lebih baik.

Dan Sikap MP-ASI. Available from: URL: https://e-

journal.unair.ac.id/index.php/MGI/article/view/3 121

Emy Y, Ayu P.S, dan Edy N. 2015.Hubungan asupan energi, lemak dan serat dengan Rasio Kadar Kolesterol Total-HDL. Penelitian Gizi dan Makanan, Desember 2015 Vol.38(2):139-147

Fitriani, Arifah. 2013. Pengaruh Intervensi Penyuluhan Menggunakan Media Leaflet terhadap Perubahan Pengetahuan Mengenai Potensi Bahaya Dermatitis Kontak dan Pencegahannya pada Pekerja Cleaning Service UIN Syarif Hidayatullah Jakarta Tahun 2013. Available from: URL: http://repository.uinjkt.ac.id/dspace/handle/1234 $\underline{56789 / 24273}$

Gustaning, Guni. 2014. Pengembangan Media Booklet Menggambar Macam-Macam Celana 
Pada Kompetensi Dasar Menggambar Celana Siswa Smk $N 1$ Jenar. Available from: URL: http://eprints.uny.ac.id/29300/1/Guni\%20Gustan ing\%2010513244017.pdf

Listiana, Lina., Purbosari, Tri. 2006. Kadar Kolesterol Total Pada Usia 25-60 Tahun. Available from: URL: http://journal.umsurabaya.ac.id/index.php/Health/article/view/7

Meili DA, Jumiyati, Emy Y (2019) . The Influence of Nutrition counseling on the Knowledge and Intake of Macro Nutrient WUS KEK in Region Work Puskesmas Sawah Lebar Bengkulu SANITAS: Jurnal Teknologi dan Seni Kesehatan Vol.10 (1). $2019: 35-45$

PERKI. 2013. Pedoman Tatalaksana Dislipidemia. Availbale from: URL: http://www.inaheart.org/upload/file/Pedoman_ta talksana Dislipidemia.pdf

Rahmawati., Rezal, Farid., Erawan, Putu. 2017. Pengaruh Konseling Gizi Dengan Media Booklet Terhadap Peningkatan Pengetahuan, Sikap, Dan Tindakan Ibu Dalam Upaya Pencegahan Gizi
Buruk Balita Di Wilayah Kerja Puskesmas Puuwatu Kota Kendari Tahun 2017. Available from:

URL: http://ojs.uho.ac.id/index.php/JIMKESMAS/artic le/view/2903

Refdi, Fhani. 2013. Pengaruh Konseling Gizi Terhadap Pengetahuan Tentang Diet Asma Dan Frekuensi Kekambuhan Pasien Asma Di Balai Besar Kesehatan Paru Masyarakat Surakarta. Available from: URL: http://eprints.ums.ac.id/27073/

Rekam Medik RSI Khadijah. 2018. Data Pasien Rawat Jalan

Riset Kesehatan Dasar. 2013. Penyakit Tidak Menular.

Ujiani, Sri. 2014. Hubungan Antara Usia Dan Jenis Kelamin Kadar Kolesterol Penderita Obesitas RSUD Abdul Moelek Provinsi lampung Available from: URL: https://ejurnal.poltekkestjk.ac.id/index.php/JK/article/viewFile/24/22 